\title{
'When will the doctor be around so that I come by?!' Geo-socio effects on health care supply, access and utilisation: experiences from Kalangala Islands, Uganda
}

\author{
Japheth Nkiriyehe Kwiringira,, James Mugisha, Mathias Akugizibwe and Paulino Ariho
}

\begin{abstract}
Background: The study set out to give an in-depth intersection of geo, eco-socio exposition of the factors relating to geography, healthcare supply and utilization in an island setting. This analysis is informed by what has emerged to be known as social epidemiology. We provide in-depth explanation of context to health care access, utilization and outcomes. We argue that health care delivery has multiple intersections that are experientially complex, multilayered and multi-dimensional to the disadvantage of vulnerable population segments of society in the study area.

Methods: We used a cross-sectional qualitative exploratory design. Qualitative methods facilitated an in-depth exploration and understanding of this island dispersed and peripheral setting. Data sources included a review of relevant literature and an ethnographic exploration of the lived experiences of community members while seeking and accessing health care. Data collection methods included in-depth interviews (IDI) from selected respondents, observation, focus group discussions (FGDs) and key informant interviews (KII).

Results: We report based on the health care systems model which posits that, health care activities are diverse but interconnected in a complex way. The identified themes are; the role of geography, access (geographical and financial) to health services, demand and utilization, Supplies, staffing and logistical barriers and a permissive and transient society. When and how to travel for care was beyond a matter of having a health need/ being sick and need arising. A motivated workforce is as critical as health facilities themselves in determining healthcare outcomes. Conclusion: Geography doesn't work and affect health outcomes in isolation. Measures that target only individuals will not be adequate to tackle health inequalities because aspects of the collective social group and physical environment may also need to be changed in order to reduce health variations.
\end{abstract}

Keywords: Geo-socio, Effects, Health, Care supply, Access, Utilization, Experiences Kalangala, Islands

\section{Background}

One important dimension of health outcomes is where the person lives. Geographic disparities in health have been a concern $[1,2]$ indeed, place is considered a determinant of health more than vectors or micro-organisms

\footnotetext{
* Correspondence: nkjapheth@yahoo.co.uk

Department of Sociology and Social Administration, Kyambogo University, Kampala, Uganda
}

(c) The Author(s). 2021 Open Access This article is licensed under a Creative Commons Attribution 4.0 International License, which permits use, sharing, adaptation, distribution and reproduction in any medium or format, as long as you give appropriate credit to the original author(s) and the source, provide a link to the Creative Commons licence, and indicate if changes were made. The images or other third party material in this article are included in the article's Creative Commons licence, unless indicated otherwise in a credit line to the material. If material is not included in the article's Creative Commons licence and your intended use is not permitted by statutory regulation or exceeds the permitted use, you will need to obtain permission directly from the copyright holder. To view a copy of this licence, visit http://creativecommons.org/licenses/by/4.0/. The Creative Commons Public Domain Dedication waiver (http://creativecommons.org/publicdomain/zero/1.0/) applies to the data made available in this article, unless otherwise stated in a credit line to the data. ical accessibility. Geographical accessibility refers to the relative ease $[4,5]$ by which health services can be reached and utilized by a population when and where the services are needed [6, 7]. Thus, a shortage coupled with longer distances travelled by people to access health services may limit access to the services and cause possible geographic disparities in utilization of health 
services $[8,9]$. Geographical access aims at analyzing the geographical dissemination of health care resources $[10$, 11]. In order to learn about the health of a population, the health of people within different geographical areas can be compared by equity, inclusion and access [12]. The explanation for geographical variations in health can be provided by socio-economic characteristics of an area. For instance, in Uganda, the north-eastern and island populations have less access to healthcare [13, 14], but the focus has been on technical factors in health care especially health infrastructure and supplies [15] and not geo-socio factors. Research on intersections of geo-socio health inequalities and exclusion factors have largely focused on HIV and AIDS among fish folk [16, 17], but not comprehensive health outcomes from an intersectionality framework. The geo-socio, service nexus in health care delivery for islanders has not been documented. In this study, we explored the intersectionality of geographical and social factors on healthcare. We provide an eco-social perspective to health provision and the production of ill health among islanders in Kalangala district. This study is a further exposition of what has emerged to be known as social epidemiology [18-20].

\section{Theoretical framework}

Hill et al., [21] describe intersectionality as a way of understanding and analysing complex social conditions. In many cases, intersections are complex but skewed, multi-layered and multi-dimensional experiences [22, 23]. The study used intersectionality theory to understand the context and processes that shape both demand and supply of healthcare relating to lifestyle, care seeking and provision of health. Increasingly, intersectionality is seen as a good approach to the analysis of multifaceted processes that produce inequality and exclusion [24].

\section{Methods}

\section{Study design}

The study used a cross-sectional qualitative [16] exploratory design [25]. Qualitative methods facilitated an indepth exploration and understanding of this island dispersed and peripheral setting. Data sources included a review of relevant literature and an ethnographic exploration of the lived experiences of community members while seeking and accessing health care. Data collection methods included in-depth interviews from selected respondents, observation, focus group discussions and Key informant interviews.

\section{Study area}

Kalangala also known as the Ssese islands are 84 islands scattered in Lake Victoria with 65 habitable islands stretching near Kenya and Tanzania. These islands are served by only 15 health centres with only one health centre IV that serves as a regional health centre. The biggest Island is Bugala and covers an area of about $296 \mathrm{Km} 2$. Kalangala district is bordered by Mpigi district to the North, Mukono to the East, the united Republic of Tanzania to the South and Masaka and Rakai districts to the West $[26,27]$.

\section{Population and study sample}

The study population were adult (males and females) and youth (in Uganda, youth are persons aged between 18 and 35 years) resident in Kalangala. No minors were interviewed. Data sources were district health officers; both technical and political including civil society and other service providers especially those in the health sector.

\section{Data collection}

Graduate research assistants were trained and matched by sex with respondents. The development of data collection tools was informed by the recommendations of Johnston et al. [28] and Israel et al. [29] whereby as much as possible the mode of data collection was adapted for minimum disruptions on the study participants. Six (6) IDI were conducted in addition to 4 Key KI along with three (3) FGD for women, 3 for men and 3 for youth. Each FGD comprised of between 6 and 10 persons. Interviews did not last more than $90 \mathrm{~min}$. We sought written consent before any interviews were conducted. Research assistants were graduates with social science research experience and familiar with qualitative research rigour and demands.

\section{Data management and analysis}

Data cleaning and analysis were concurrent with data collection. For analysis, the local language versions of transcripts were first translated into English before importing the transcripts into NVivo version 11.0 for coding and analysis. Data was analyzed using content thematic approach, guided by themes contained in the data collection instruments. These themes were further refined following multiple readings of interview scripts to better understand the data. Typical quotations have been used in the presentation of findings. Identities of participants have been masked. We used concurrent triangulation during data analysis to ensure validity and reliability in the understanding of all intersecting issues.

\section{Ethical considerations}

Ethical clearance was sought from the TASO REC (TASOREC/021/2020-UG-REC-009) which considered all ethical issues in the protocol. After review and approval, the proposal was again submitted to UNCST (SS506ES) for accreditation before data collection. Written informed consent was obtained from all study 
participants. All methods were performed in accordance with the relevant guidelines and regulations.

\section{Results}

We report based on the health care systems model which posits that, health care activities are diverse, but interconnected in a complex way [30,31]. The results are presented along the identified themes and subthemes as;

\section{i) The role of geography}

- Location as a barrier to service access

- Poor communication, transport and a transient population

- Seasons and healthcare

\section{ii) Access (geographical and financial) to health services, demand and utilization}

- Staff attributes and (ir)regularity

- Late opening and complicated access to health care facilities

\section{iii) Supplies, staffing and logistical barriers}

- Irregular medical supplies and stock outs

- Poor support supervision and poor health delivery

- Poor living and working conditions

\section{iv) A permissive and transient society \\ v) Unusual generosity and unconventional sharing ' $\mathrm{Ffe}$ tulibalwadde' 'we're sick people -leave us alone'}

- A risk economy and many cultures

- Unusual reasons to share HIV results

\section{The role of geography}

\section{Location as a barrier to service access}

Kalangala consists of 84 islands, 56 of these have no health centers meaning that, many patients have to cross over from one island to another in search of healthcare. In addition, Kalangala district has no hospital. According to the Ministry of Health norms, to adequately cover its population of 54,100, the district should have a total of 16 health centers in addition to a hospital. Our findings indicate that health infrastructure in Kalangala is limited with the nearest hospitals in Entebbe $(30-120 \mathrm{~km})$ and Masaka (40-114 km). This geo-physical setting compromises the power of social capital, and social networks especially that communications, and transport means were unreliable. For far flung islands like Mazinga, and Bubeke, journeys to health centres were reported to take between 3 and $4 \mathrm{~h}$ by boat to access hospital level care. Poor health access was also linked to poverty especially those in hard-to-reach and hard to leave areas. Community outreaches were at times cancelled due to bad weather.

Usually, there are extensive debates and considerations in view of the fear to get worse on the way; given the long journeys that are precarious including the fear to lose more than necessary along with the uncertainty of finding the health facility open including not being attended to ... most locations in Kalangala did not have reliable telephone signals for timely communication ... District health official.

This complexity meant that, on one hand, the sick could not get timely attention, while on the other hand, health workers and supplies could not get to clients at facility level in time. On the whole, this precipitated poor health outcomes including high morbidity and mortality that were also poorly captured and documented due to underreporting given that people fell sick and died outside health facilities.

\section{Poor communication and transport}

The challenges of unpredictable transport sometimes made it impossible for the chronically and critically ill to keep clinical appointments including drug refills led to undesirable outcomes including dropping out of care. In some cases, such delays went up to a month of delay without treatment. This situation affected commuters that had two homes, one on the island and another off the island. Severe and chronic sicknesses were poorly handled in such locations including loss to care. Because of these transport and logistics related challenges, people usually showed up at the health centres when very sick. This increased both the morbidity that was caused by failure to get back for review as well as timely referral when nonresponsive to treatment as well as mortality. Admittedly, there was very low health literacy as well as overall literacy and poor education indices on account of poor access, and delivery. 
'Poor transport is compounded by the fact that, the safer modes of transport like ferries do not operate at night and yet many (health) emergencies present at night when time is of the essence ... ' Private not for profit health service provider

Other risk multipliers on the island were related to small, slow water crafts that also leaked, overall poor marine safety due to lack of standards especially the lack of life jackets which increased the risk to passengers on case of an accident or need to evacuate the marine vessel. In the absence of public transport, travel means had been left to private providers that were motivated by profits making boat hire services prohibitively high for an average person. Because of the high costs of transport, community out reaches were sometimes cancelled. When community outreaches became interrupted, medications to the chronically could not be delivered. Transport was complicated by the substandard marine transport services and equipment mainly of canoes and poorly built boats. Safety concerns were paramount to service providers and yet, the health needs of the populace were dire. This dilemma especially the untimely delivery of supplies did not contribute to good health outcomes. Nkese Island near Kenya was specifically pointed out as having bad weather. The health outreaches to this island were the most unsuccessful. It was reported that there had been cases of losing clinical samples and supplies such as blood and testing kits after they fell in water due to turbulent waters.

'... engines have fallen off boats. This is imminent danger... people have been lost for several hours including ending up in the wrong place sometimes resulting in running out of fuel. There are also cases of patients dying while transport is arranged especially that many usually fail to meet the emergency fare to referral facilities..! Private Not for Profit Health care provider

As a coping mechanism, patients with chronic and terminal illnesses pooled money to travel as a group so as to cost share and reduce costs. In other cases, one person would be sent to collect supplies in the case of ARVs for the entire group. This in itself had associated risks and uncertainties including the possibility of mix-ups or a total loss of the package. However, the fear of disclosure and stigma had at times worked against such collective action in care seeking. In a bid to cope, whenever possible, especially for ANC and deliveries that were not emergencies, people planned and travelled early so as to avoid emergencies and last-minute travels that posed great uncertainty. Prior travel arrangements were beset by other associated costs of upkeep that not all could afford. Such and similar challenges inadvertently meant poor health delivery including loss to follow up with both chronic and terminal ailments getting worse. Kalangala being hard to reach and leave meant that, support supervision was also expensive, irregular and ineffective. This left many gaps in staff work hours and facility service times related to signing out for weekends earlier than expected (sometimes on Wednesday or Thursdays) and reporting back for the week on Monday or Tuesday. This was partly explainable from the lack of effective family services such as schools, housing and other life style amenities that made service providers migratory. For example, many civil servants had their families and investments on the mainland especially Masaka, Jinja, Rakai, Kampala, and Entebbe.

\section{Seasons and health care}

Treatment and care were affected by seasons and weather which made costs for transport expensive and sometimes impossible due to volatile waters.

'Even if you have all the money in the World, once the lake is turbulent, you cannot travel ... here we only go for treatment when we have money because it is a season for fish and therefore, we have money, but also when the lake is calm. We have lost some people because the lake was not navigable ... ' Long stay resident/ islander.

For the chronically and critically ill, lives were at risk when bad weather impeded travel. It was reported that, both patients/ the general population as well as health care providers would at times be forced to cancel journeys to health centres to provide treatment and support on account of poor weather conditions. Geographical and locational factors such as these, significantly influenced health seeking and influenced health outcomes in an unplanned manner. Almost the same problems faced by the population, faced health workers as well. With a few exceptions, the further away the healthcare services, the lower their standards and use. While merely being close to a health facility doesn't always guarantee better access, (especially due to cost and cultural factors), in Kalangala, the further away the facility was located, the more it was less likely to have qualified staff, no supplies and harder to be accessed. Over all, health care was worse for vulnerable groups and this was unnoticed and largely underreported. 
Access (geographical and financial) to health services, demand, and utilization

Staff attributes, (ir) regularity, availability and awareness of staff itinerary

Staff attributes such as being approachable and the knowledge about their qualifications meant a lot. The more staff were thought, perceived and known to be qualified (clinical officers, midwives and nurses) the more people would make it a point to seek services at such a facility. This was in addition to being reported to be available for duty by proxies and personal indicators; 'Their car', the office/ house being open, being seen that day or week-end in town etc., the more people encouraged each other to seek care from these facilities (especially women and children). Staff availability was a key care seeking driver. There were indications that, the more staff were known to be qualified (clinical officers, midwives and nurses), the more people encouraged each other to seek care from these facilities Perceptions of health staff kindness and willingness to listen endeared patients not only to seek services, but also to wait and the willingness to postpone treatment and review 'just to be seen by a particular health staff.' 'When will the doctor be around so that I come by??

\section{Late opening and complicated access to health care facilities}

Few and short opening hours were linked to lack of staff housing at health facilities, and long travel time that was made worse by bad weather with some staff absconding from duty. Although health worker deployment is estimated at $80 \%$ within the district, the working conditions had practically worked against these staffing norms.

'Most health facilities were closed on weekends, holidays, during bad weather, at night and for the most hours during the day because of late opening and early closing times ... ' Female FGD participant.

Without a risk allowance and poor facilitation, health workers in Kalangala faced a very expensive life which compromised their effectiveness. This reality made sickness an ordeal especially; when a partner or any person of help was away, when low on cash to hire a boat and more so, in an emergency or critical sickness or accident. This was so bearing in mind the likely long waiting hours at the health facility. Antenatal Care (ANC) was further complicated when a spouse would be required at the facility by health workers especially in dealing with Prevention of Mother to Child Transmission (PMTCT) cases and family planning among others. Such a requirement increased all costs of care and treatment. Spousal presence was also unattractive especially that men had many hustles out of which they made ends meet. Some men also perceived ANC as female spaces in which men were exempted. In response, care seeking was sometimes delayed or came at high cost on the household. These were at times pre-cursors to domestic violence, violence against women and sexual and gender-based violence.

\section{Supplies, staffing, and logistical barriers Irregular medical supplies and stock outs}

Irregular medical supplies were reported as common and contributing to non-adherence leading to poor treatment outcomes. Adherence and retention in chronic and terminal care were reported to be very difficult in a context of irregular supplies and stock outs. Irregular supplies affected both care seeking and health delivery in that, patients were reluctant to take long journeys without certainty of service especially that some trips were so expensive and required in excess of $100 \mathrm{l}$ of fuel to travel in the case of private boat hire, such cost estimates were to the tune of about UGX 300,000/(about US\$ 85.00). Transport difficulties were most dire on the islands of Mazinga, Bubeke, and Jana. The results were poor health outcomes in form of late referrals, worsening conditions that would have been treated at less cost, permanent impairment and sometimes death.

\section{Poor support supervision and poor health delivery}

The geographical location of Kalangala islands also meant that support supervision was expensive, irregular and ineffective. This left many gaps in staff work hours and facility service times related to signing out and absence on weekends earlier than expected; (sometimes on Wednesday or Thursdays) and reporting back for duty on Monday or Tuesday of the next week. This was explainable given that a number of technical staff had their families and interests on the main land and therefore, had divided time between the work station -Kalangala and other concerns off the island. It was also reported that;

\section{'For whoever got a breakthrough (financial or career -education related) they quickly migrated to the mainland where they perceived more and better op- portunity and hence less investment on the islands.' Local government official}

This process had negatively affected the island service delivery and broader investment potential. Due to poor working conditions and weak support supervision, most diagnosis and treatment were provided by junior staff at nursing officer level and below, who treated patients based on symptoms than diagnosis. Because of this, asymptomatic cases were missed in treatment. This also led to delayed referrals and the associated complications. 


\section{Poor living and working conditions}

The poor living conditions were partly because islanders regarded the fishing communities as temporary places to work rather than places to improve. This was especially due to the high-water table which made the delivery of good sanitation and proper environmental health costly in terms of water borne systems and associated costs. Respondents reported poor hygiene (that was also evident through observation) with the associated diarrheal diseases. Poor waste management was widespread coupled with pollution from dumpsites and burning of refuse in this otherwise pristine getaway to white sand beaches that were out of reach for the local residents. Majority of dwelling units were congested, small, multipurpose and poorly lit; wood, cardboards, mud and wattle structures which compromised the essence of 'housing' as a basic need. This housing provision was not able to provide cover from extreme conditions for all age groups and population categories. This in itself meant that young children and the infirm would not get request conditions to recuperate in such kinds of shelter. Therefore, for the low-income earner, some discomfort and the lack of care and comfort were permissible. This was partly due to the unpredictable income streams that were weather dependent. The crackdown on illegal fishing hurt many livelihoods by cutting off incomes for many households and related service providers. This was especially that there were no alternative income measures or the provision of social safety-nets. The poor living conditions were further linked to the sociodemographics including household poverty and poor service delivery. Services such as safe water, sanitation, health and education facilities were often poor or entirely absent. Demands of the fishing industry, the strong occupational identities and incentives to remain in fishing negatively affected the educational outcomes of formal schooling.

\section{A permissive and transient society Unusual generosity and unconventional sharing 'Ffe tulibalwadde' 'we're sick people -leave us alone'}

It was reported in a male FGDs that women belonged to the wider community. This notion of women as 'a common wealth' was related to the uncertainty of life with men arguing that when they go fishing, they are neither sure when nor whether they will comeback. They therefore argued that, instead of letting their women starve while they are away, it was pragmatic to let someone else take charge' and look after their women. One quipped that, there was 'no point in restricting another persons' opportunity when you're away ...! There was a sense of 'brotherhood' as regards sexual partners on the islands.
'The reality that fishermen did not move with their wives made them readily available husbands to females at the landing site. Whoever was present was the husband.'

District official.

'You cannot guarantee that I am going to the lake and I will comeback. None is sure!'

IDI Fisher man.

While this was the view held by men, it was interesting that women were equally unbothered about the prospect of entertaining another man while the man of the house was away. Women in a FGD asserted that;

'... you only welcome your partner when you see him! He also knows this! It is ok if he finds you not ready for him. He knows that everyone does this!'

Men equally posited that; :

Suppose I die? What will happen to her? Women cannot separate us; instead, women should unite us...' Male Key informant

'A woman here has about five (5) husbands and this is normal. There is no worry about this ... ' $\mathrm{KII}$ -Local Government official

Such practices were reported among those in vibrant fish trade and therefore having regular and reliable, adequate income streams. It was argued that most fishermen were used to this life style of living in the moment. Life was simple, without a care.

'Every morning is just another day and the lake will provide fish and therefore money. There is no reason to worry and stress out. Male boat owner.

If there is a lake, fish, boats and men, your needs are sorted!

IDI -long a female resident.

If a woman stays in one place for about 3 months, she loses value ... you need to meet new people. As such you must go to a new place so as to gain value.'

Female Commercial Sex Worker.

'Fishermen here bet on the first person to sleep with a new woman in an area.'

KII -Health worker. 
After everyman on an island has used you, you lose value. As such, you find a coping mechanism and have to move elsewhere to gain value since you are new after you have repackaged your identity.'

Female Commercial Sex Worker.

In this way, prostitution is a livelihood in its own right. It was unique that, there was a form and type of 'culture' that allowed for being liberal with partners. This acculturation has been extended to the non-fishing community and residents on the island.

'Even us who are educated and delivering services in this place, we have many challenges at family level. The mainland is very far; our families are not here. As a result, we have developed a form of 'divided affection' between our families back home and the women here know this. For instance, over the weekend, University students from Nkumba storm this place dressed to kill. Campus students have made this a routine to come and make money from this place as we also spend more time with them. These 'flowers' are very popular and famous among both salary earners and successful fishermen. 'Working here greatly changes one's perspective of life. There is a totally different culture here.

It is very difficult to be faithful in this place.' Male Civil servant.

Attractive females in the area are called 'flowers' that were to be 'visited, plucked and smelled'. Men reported that, trust seemed to increase with females they knew less about and had no reason to ascribe sexual risk to them. Surprisingly, while fishermen did not care much about safe sexual practices, they equally asserted that, they know that they're sick. This was because of what they knew about the causes of HIV. However, they also knew that, life is short and therefore to be enjoyed. Health workers reported that unlike other locations, ' $a$ negative HIV result was most unbelievable and always doubted ... than a positive one ... 'Health workers indicated that;

It took a lot of counselling and persuasion to let a person take a negative result as true. Those that were able, went on to carry out other tests to be sure about such an unlikely test result.' Health service provider

\section{A risk economy and many cultures}

In Kalangala, risk had been normalized in all aspects of life including the norming of hyper risk episodes to include sexual relations. People were liberal in all aspects of life including being seen naked or having sex without privacy. On the whole, there was no secrecy about sex. It was reported that unprotected sex went for an entry price of Ugx 20,000, (about US\$5.00) whereas protected sex was negotiable from about Ugx 5000 (about US\$1.3). There were many teenage and adolescent mothers, many school dropouts and single parents. This was partly due to the attractive lifestyle associated with cash derived from fishing and commercial sex work as seen in those that dropout of school. Lack of progression in school was also linked to the inadequate adolescent friendly services on the islands largely because the environment is not attractive to skilled health workers. The islands were also a multi-cultural setting with many tribes and cultures with people from across the east African region.

'Here we have almost everyone, including people from Tanzania, Kenya, Rwanda, Burundi, Congo, Sudan, South Sudan, Somalia, and from all over Uganda that make socialization complex' ... Local council leader

The multiple ethnicities were amidst limited health services as well as other social service and primary healthcare deficits that partly associated with why HIV was first reported on these islands in Uganda.

\section{Unusual reasons to share HIV test results}

While HIV results and personal information are meant to be confidential, there were cases of volunteering to share test results among colleagues in an effort to clear doubts about one's HIV status. This was the case especially when one wanted to win the favor of a prospective partner or dispel a rumor about one's health status to serve as a baseline and basis for trust and acceptance among those they valued or courted. In other cases, people volunteered to share not their HIV test results, but the results of others as a form of 'social responsibility.' Such persons argued that 'if you see a pit, you warn colleagues.' While this was unethical, the perception was that since, test services were inaccessible (far and irregular) part of being a brother' keeper was to 'share' such information among people one cares about. For those whose privacy was violated, this was a source of stigma. Because negative HIV test results were seldom, a negative result was peculiar and inadvertently increased ones sexual 'value'. There were reports of some people seeking to obtain negative test results through bribery and falsification of results. This was one of the challenges related to the reliability of test results. The full extent of such practices was not established. 


\section{Discussion}

We argue that, while there's a web of causation to poor health outcomes as a result of geo-social factors [32], there should be much more effort in finding the spider causing this web. Table 1 presents the mapping of these geo-social challenges as well as proposed recommendations.

From Table 1, the highlighted challenges resulted in poor service delivery, access, utilization and poor follow-up and lost care in case of chronic and lifethreatening situations with frequent resort to selfmedication [49], and polypharmacy [50]. Other undesired outcomes were giving up prescription medicine to a friend or relative including the 'borrowing' of medicines in order to avoid the inconvenience and costs of treatment. The reported pharmaceutical altruism was occasioned by running out of medicine by an acquaintance that was not able to afford accessibility and treatment costs, emergency situations and the convenience of sharing. We found a social context of medicine sharing relating to the same reasons why people shared [51] other resources.

When and how to travel for care was beyond a matter of having a health need/ being sick and need arising [52-55]. Rather, it was when the means and conditions permitted in view of weather, availability of means and money [55-57] as well as opening hours at the health facility and the odds of finding a health worker. Even when there were emergencies, it was not easy to get care. Weather and the season on the lake and fish catches meant having money or not; being broke or having liquidity $[58,59]$. In this sense, emergency care was least effective since very sick people cannot hold out for about three hours on rough waters. Because of this, emergency and chronic diseases that would have otherwise been managed became fatalities and in some cases becoming sources of disability and complications $[60,61]$. One common example was prolonged labour and cases of obstetric fistula. The situation on the islands was made worse by a poor transport system, characterized by irregular transport services and boats that were in poor conditions especially being substandard $[56,62]$.

While society tends to place equal responsibility on individuals for compositional health risks, it offers inequality $[1,63]$ in the means to deal with them. This was illustrated by the exotic tourist destinations on Ssese islands that are sought after places by the highclass and the elite. However, these locations are private and not typical of the average life style on the islands. The tourist resorts are insulated against the everyday limitations of the islanders through the use of speedboats, health checkups including air ambulance services among other composite features afforded by the wealthy.

\section{Intersectionality in perspective}

Where a person lives, is as important as who they are in terms of health [64-66]. Geography, culture, context, health and place [12] especially income, education, relations, beliefs and infrastructure/ attitudes/ leisure have different meanings attached to life and in a given place $[20,67]$. In Kalangala, Kulya sente kivubi meant living in the moment and for the moment. It was widely held that, the riskier episodes one experienced and survived; the more risk appetite one seemed to get and be aloof to safety. Such findings have been previously reported among fishing communities [58]. In all ways, there was no need and never a worry about tomorrow [58, 68]. While this was not new, it had a more dramatic effect in Kalangala. This mindset did not consider poor health or any other cause of future failed income. Individuals and households are molded and influenced by their local environment. Local circumstances are key in understanding people' health [16, 24, 69]. Where you live, work, play largely explains the choices made and place explains a lot of this socio-spatial component since place exerts an influence on a range of health outcomes e.g., smoking and alcohol consumption among fishermen [58, 70]. At micro-level, individual/household and community factors also affected access and use of health services. This is the context of health care in terms of access and affordability [71].

Unreliable, unpredictable, unsafe and unaffordable transport [72-74] resulted in poor follow-up and lost care in case of chronic diseases and life-threatening situations with frequent resort to self-medication, and polypharmacy [75]. Other effects were the giving of prescription medicine to a friend or relative including the 'borrowing' of medicines in order to avoid the inconvenience and costs of treatment, so long as they had the same symptoms and symptom matching, past illness experience [76] or believed that the one sharing had an idea about the disease at hand or knowledge about the medicine [77]. This resulted in high risks of drug resistance and poor recovery by patients who faced a number of financial and geographical challenges.

While geographical access in the country has improved [78], Kalangala district had few health facilities. Even with income earning opportunities in the fishing economy, the living conditions were generally poor. This was common for most landing sites in Uganda. Overall, this negatively affected the lives and health outcomes of fisher folk and islanders especially due to unsanitary living and crowding. The various service delivery challenges on Kalangala islands need service modes that are not contingent on time of day, weather and season or being well-off or not. Overall, other aspects of life; home, work and school (it was quite easy to drop out of school) were also dependent on weather, and seasons. On 
Table 1 Challenges, exclusion, health outcomes and recommendations

\begin{tabular}{|c|c|c|c|}
\hline Category & Source of Exclusion & Health Outcomes & Recommendations \\
\hline $\begin{array}{l}\text { The } \\
\text { uneducated } \\
\text { especially } \\
\text { Adolescents } \\
\text { and youth }\end{array}$ & $\begin{array}{l}\text { Poor health outcomes related to } \\
\text { education being despised in favour } \\
\text { of quick returns from fishing } \\
\text { 'having a partner with boats is a } \\
\text { destination status...' } \\
\text { Negative peer influence and } \\
\text { incorrect health information } \\
\text { among the island community }\end{array}$ & $\begin{array}{l}\text { Limited access to health } \\
\text { information results in poor } \\
\text { health seeking behaviour } \\
\text { Early, teen and unplanned } \\
\text { pregnancies } \\
\text { Delay in testing for HIV and } \\
\text { continued transmission of } \\
\text { the virus }\end{array}$ & $\begin{array}{l}\text { Appropriate sexual and } \\
\text { reproductive health education } \\
\text { Use positive role models to } \\
\text { challenge negative norms } \\
\text { Create micro-targets on each island } \\
\text { to reach young people with clinical } \\
\text { services } \\
\text { Provide support services for key } \\
\text { populations and link with CBOs } \\
\text { Work with "gatekeepers/ and all } \\
\text { stakeholders" to emphasize } \\
\text { adolescent health, women welfare, } \\
\text { education attainment and health } \\
\text { as a means of personal and } \\
\text { community development }\end{array}$ \\
\hline
\end{tabular}

The Poor health outcomes related to Limited access to health uneducated education being despised in favour information results in poor especially of quick returns from fishing Adolescents 'having a partner with boats is a and youth destination status...' Negative peer influence and incorrect health information among the island community health seeking behaviour Early, teen and unplanned pregnancies Delay in testing for HIV and continued transmission of the virus
Pregnant

Single

Adolescents and Women in far flung islands
Negative cultural attitudes towards teenage pregnancy, estrangement and limited resources

(n)

Limited access to health services out of for fear of discrimination Consequences of termination of pregnancy leading to death
Appropriate sexual and reproductive health education Use positive role models to challenge negative norms

Create micro-targets on each island to reach young people with clinical services

Provide support services for key populations and link with CBOs Work with "gatekeepers/ and all stakeholders" to emphasize adolescent health, women welfare, education attainment and health as a means of personal and community development

Recruit and train peer educators to serve as change agents Use social media for dissemination of youth-friendly health services Engage with communities on why delivering babies in health facilities is safer for both mother and baby Explore and adopt the use of technology and telemedicine for example the use of medical drones in remote locations Implement express of supplies and delivery for key populations.

Requirement of husbands/ spouses having to accompany pregnant woman to health facility for ANC Dependence on males/ spouses for permission and resources to attend clinic

Internalized stigma

Sero-

Positive

Poverty and the lack of resources

persons
Pregnant women without a willing partner are discriminated against and

thus do not regularly attend ANC

Pregnant women resort to bringing any man available which works against the intended benefits of male involvement

Proxy husbands can result in GBV

Delay in seeking ARV treatment

Take ARVS in hiding Do not have resources to get refills for ARVs
Conduct Sexual and Reproductive Health Behavioural Change Communication (SRHBCC)

targeting men to promote responsibility

Empower women to be independent and able to access health care services.

Invest in research that would cut costs of travel and delivery in terms of time and consumables. Upgrade the existing health facilities to be able to host and work with the new -proposed technology

Explore alternative sites for distributions of ARVs and more practical modes of delivery. Increase income earning and focus on Poverty alleviation interventions through skilling, value chains and community infrastructure for transportation and health care services

\section{Reviewed Literature}

Dingake, O. B. K. (2018) [33].

Engel, D. M. C., Paul, M.,

Chalasani, S., Gonsalves, L.,

Ross, D. A., Chandra-Mouli, V., \& Ferguson, B. J. (2019) [34].

Ong, K. K. X., Ng, J. S., Om, C., Chhoun, P., Tuot, S., \& Yi, S. (2020) [35].

Ali, M., Cordero, J. P., Khan, F., \& Folz, R. (2019).

Dingake, O. B. K. (2018) [33] Engel, D. M. C., Paul, M.,

Chalasani, S., Gonsalves, L., Ross, D. A., Chandra-Mouli, V., \& Ferguson, B. J. (2019) [34]. Ong, K. K. X., Ng, J. S., Om, C., Chhoun, P., Tuot, S., \& Yi, S. (2020) [35].

Ali, M., Cordero, J. P., Khan, F., \& Folz, R. (2019).

Senior, K. A., \& Chenhall, R. D. (2012) [36].

Woog, V., \& Kågesten, A.

(2017) [37].

Kennedy, E. C., Bulu, S., Harris,

J., Humphreys, D., Malverus,

J., \& Gray, N. J. (2013) [38].

J., 
Table 1 Challenges, exclusion, health outcomes and recommendations (Continued)

\begin{tabular}{|c|c|c|c|c|}
\hline Category & Source of Exclusion & Health Outcomes & Recommendations & Reviewed Literature \\
\hline Male Youth & $\begin{array}{l}\text { Negative masculinity norms: fear of } \\
\text { betraying culture especially letting } \\
\text { women take control in decision } \\
\text { making Preference for traditional } \\
\text { healers on account of } \\
\text { confidentiality, accessibility and } \\
\text { negotiated payment terms. } \\
\text { Leave school to fish }\end{array}$ & $\begin{array}{l}\text { Men seek health services } \\
\text { when they are in gross pain } \\
\text { and the medical condition } \\
\text { has progressed } \\
\text { Alcohol and drug abuse } \\
\text { Do not disclose full } \\
\text { information } \\
\text { Negative resilience and } \\
\text { masculinities. }\end{array}$ & $\begin{array}{l}\text { Mobile services and community } \\
\text { outreaches } \\
\text { Explore the viability of Health } \\
\text { camps } \\
\text { Conduct community level 'test and } \\
\text { treat' outreach campaigns for the } \\
\text { most at-risk key populations. Ex- } \\
\text { plore the use of male peers to pro- } \\
\text { mote appropriate male } \\
\text { involvement and reach males }\end{array}$ & $\begin{array}{l}\text { Easton, S. D., Saltzman, L. Y., \& } \\
\text { Willis, D. G. (2014) [45]. } \\
\text { Lehman, P. (2007) [46]. } \\
\text { Fleming, P. J., Lee, J. G., \& } \\
\text { Dworkin, S. L. (2014) [47]. } \\
\text { Sileo, K. M., Fielding-Miller, R., } \\
\text { Dworkin, S. L., \& Fleming, P. J. } \\
\text { (2019) [48]. }\end{array}$ \\
\hline
\end{tabular}

account of geography, far off islanders that needed better care on the main land, bicycles, motor cycles and vehicles did not have a significant role in care as is the case for other parts of the country. And yet, private boat ownership was not possible for almost the entire population. This made medical emergencies and referrals very unique and much more complicated than in other parts of the country. This makes Kalangala unique in all aspects of health care and calls into discussion the need for affordable public transport as part of the health delivery model in Kalangala.

Physical access and personal welfare for health care staff including housing are important factors in health care provision, access and utilization by the population on a regular basis. Private facilities closed the gap for those that can afford (the well-off), but also where they existed; their access was by affordability and not spatial proximity $[79,80]$. Private facilities had an income barrier, at utilization than at access, while most public facilities had long distance as barrier [81]. Therefore, private health facilities are crucial in improving health access if the affordability issue is addressed. This is a recourse to welfare improvements and poverty reduction [82] in health care delivery.

Knowing someone (irrespective of rank and title) at the public health facility (a guard or even a cleaner) was perceived as useful since they relied important information such as availability of drug stocks, presence of staff and generally when to seek better services. This was a form of social capital and a very big asset. The longtime lost in travelling especially for pregnant and lactating mothers was including the various costs associated to access and receiving treatment, acquiring medicines and returning home. Such costs were often a disincentive to care-seeking among poor people [83] even when medicine were available and free. While women have traditionally been the ones keener to seek health care than men [84], the picture in Kalangala was different. The transport challenges had a gender dimension to access and affordability. There have been indications that outof-pocket payments are inequitable and exploitative given that they aggravate poverty with likely poor treatment outcomes $[85,86]$. In the case of chronic sickness, out of pocket costs more often led to disposal of assets such as fishing nets and boats. Where this was not possible, the other option was the acquisition of debt. Similar findings have been reported elsewhere [87, 88].

We posit that, individuals do not exist in isolation but, rather in places within the environments and spaces [89, 90] that are affected by seasons [91] as being favorable or not. This recognizes that, people exist in complex setups that create and shape health [92-94]. Individuals are not separate from the geo-social context with health outcomes as part of a broader system including how well responses to health needs [89] and demands are met. There is an urgent need to explore the interactions between all variables in order to understand the complexities of multiple causality in explaining health outcomes. We are convinced that, some places explain health inequalities more than others.

\section{Study limitations}

This was a qualitative study that did not collect data from all islands in Kalangala district and yet, each island has its own unique features, ranging from income, culture and service infrastructure. Even then, this study offers a qualitative exposition of the geography -culture nexus of healthcare access, delivery and outcomes. These findings offer a thick description of the goings on in Kalangala that can be a basis for further inquiry. There is need to have a fully blown study that represents all islands in the district so as to inform actionable interventions for each island location based on quantitative evidence.

\section{Conclusion}

Income and cost of care are crucial when a choice of care is being made. Physical access and personal welfare (income and education) are as well important factors in health care access and utilization. A motivated workforce is as critical as health facilities themselves in determining health care outcomes. It is useful in the long-run to treat the root causes, instead of focusing on symptoms. This is the call to see places as more than the sum 
of the current human populations living and dying within them. In a great detail, places form people as much as places are formed from people's actions. Geography doesn't work and affect health outcomes in isolation. Social status and livelihoods mediate the role of geography on health outcomes. Health variations, delivery, demand and access are a commentary on general welfare in a population. Measures that target only individuals will probably not be adequate to tackle health inequalities because aspects of the collective social group and physical environment need to be changed in order to reduce health variations.

\section{Abbreviations}

ARVs: Anti-Retroviral; GBV: Gender Based Violence; ANC: Antenatal Care; SBCC: Sexual and Behavior Change Communication; RH/FP: Reproductive Health and Family Planning; CBOs: Community Based Organizations; PNFP: Private Not For Profit; CSW: Commercial Sex Worker; IDI: In-depth Interview; KIl: Key Informant Interview; FGD: Focus Group Discussion; PMTC T: Prevention of Mother To Child Transmission; PHC: Primary Health Care; $\mathrm{MCH}$ : Maternal and Child Health

\section{Acknowledgments}

The authors would like to specifically thank Simeo Ssebukulu, Phenekus Mulongo and Joan Akullo for their contribution to the entire study in terms of mobilization and technical assistance. We are also indebted to district leaders as well as the study participants and the entire study team for their contribution without which this study would not have been a success.

\section{Authors' contributions}

Japheth Kwiringira -PhD contributed to the conception of the topic, design of the study, seeking approval, data collection, analysis and drafted the manuscript. James Mugisha -PhD revised the manuscript. Akugizibwe Mathias-MA sought the study approval and revised the manuscript. Paulino Ariho -MA was key in conceptualization. All authors contributed to revising and approved the final manuscript.

\section{Authors' information}

Japheth Kwiringira -PhD is a Lecturer of Sociology in the department of Sociology and Social Administration, Faculty of Arts and Social Sciences, Kyambogo University.

James Mugisha -PhD is a senior lecturer of social work in the department of Sociology and Social Administration, Faculty of Arts and Social Sciences, Kyambogo University.

Mathias Akugizibwe-MA is an Assistant lecturer of Sociology in the department of Sociology and Social Administration, Faculty of Arts and Social Sciences, Kyambogo University.

Paulino Ariho -MA is an Assistant lecturer of Sociology in the department of Sociology and Social Administration, Faculty of Arts and Social Sciences, Kyambogo University.

\section{Funding}

This study was supported with funding by Kyambogo University Competitive Research Grants 2nd call for proposals and Research Grants Adhoc Committee. The funders did not play any role in the study design, implementation procedure, analysis, interpretation or even drafting the manuscript.

\section{Availability of data and materials}

All the data sets that were used for this study are available and in case of need, they can be accessed from the corresponding author (Japheth Kwiringira -PhD) upon request.

\section{Declarations}

\section{Ethics approval and consent to participate}

This study protocol was reviewed and cleared by Research and Ethics Committee of The Aids Support Organization (TASO)-TASOREC/021/2020-UG-
REC-009 and Uganda National Council of Science and Technology (UNCST)SS506ES. Before participating in the study, all study participants provided informed written consent. All methods were performed in accordance with the relevant guidelines and regulations.

\section{Consent for publication}

Not Applicable.

\section{Competing interests}

All authors declare that there are no conflicts/competing interests with regard to this manuscript.

Received: 18 June 2021 Accepted: 20 October 2021

Published online: 26 October 2021

\section{References}

1. Behringer B, Friedell GH. Appalachia: where place matters in health. Prev Chronic Dis. 2006;3(4):A113.

2. Hartley D. Rural health disparities, population health, and rural culture. Am J Public Health. 2004;94(10):1675-8. https://doi.org/10.2105/AJPH.94.10.1675.

3. Gargon E, Gurung B, Medley N, Altman DG, Blazeby JM, Clarke M, et al. Choosing important health outcomes for comparative effectiveness research: a systematic review. PLoS One. 2014;9(6):e99111. https://doi.org/1 0.1371/journal.pone.0099111.

4. Okwaraji YB, Cousens S, Berhane Y, Mulholland K, Edmond K. Effect of geographical access to health facilities on child mortality in rural Ethiopia: a community based cross sectional study. PLoS One. 2012;7(3):e33564. https:// doi.org/10.1371/journal.pone.0033564.

5. Ssetaala A, et al. Components of antenatal care received by women in fishing communities on Lake Victoria, Uganda; a cross sectional survey. BMC Health Serv Res. 2020;20(1):1-9.

6. Fortney JC, Burgess JF Jr, Bosworth HB, Booth BM, Kaboli PJ. A reconceptualization of access for 21st century healthcare. J Gen Intern Med. 2011;26(2):639. https://doi.org/10.1007/s11606-011-1806-6.

7. Morgan M. Patients' help-seeking and. Access to health care; 2013. p. 61.

8. Haynes R. Geographical access to. Access to health care; 2003. p. 13.

9. Leite MJVdF, Dantas A, Roncalli AG. Epidemiology and Place: A Spatial Area for Health Analysis. HOLOS. 2015;8:357-67. https://doi.org/10.15628/holos.2 015.2854 .

10. Cutchin MP. Putting health into place: landscape, identity, and well-being JSTOR; 2000.

11. Kearns R, Moon G. From medical to health geography: novelty, place and theory after a decade of change. Prog Hum Geogr. 2002;26(5):605-25. https://doi.org/10.1191/0309132502ph389oa

12. Comber AJ, Brunsdon C, Radburn R. A spatial analysis of variations in health access: linking geography, socio-economic status and access perceptions. Int J Health Geogr. 2011;10(1):1-11. https://doi.org/10.1186/1476-072X-10-44.

13. Bbaale E. Factors influencing childhood immunization in Uganda. J Health, Popul Nutr. 2013:31(1):118.

14. Wilunda C, et al. Determinants of utilisation of antenatal care and skilled birth attendant at delivery in south west Shoa zone, Ethiopia: a cross sectional study. Reprod Health. 2015;12(1):1-12.

15. Edward B. Factors influencing the utilisation of antenatal care content in Uganda. Australas Med J. 2011;4(9):516-26. https://doi.org/10.4066/AMJ.2 011.849

16. Kiwanuka N, Ssetaala A, Mpendo J, Wambuzi M, Nanvubya A, Sigirenda S, et al. High HIV-1 prevalence, risk behaviours, and willingness to participate in HIV vaccine trials in fishing communities on Lake Victoria, Uganda. J Int AIDS Soc. 2013;16(1):18621. https://doi.org/10.7448/IAS.16.1.18621.

17. Lubega M, Nakyaanjo N, Nansubuga S, Hiire E, Kigozi G, Nakigozi G, et al. Risk denial and socio-economic factors related to high HIV transmission in a fishing community in Rakai, Uganda: a qualitative study. PLoS One. 2015; 10(8):e0132740. https://doi.org/10.1371/journal.pone.0132740.

18. Oakes JM, Kaufman JS. Methods in social epidemiology. Bronx: Wiley; 2017

19. Kawachi I, Berkman L. Social cohesion, social capital, and health. Soc Epidemiol. 2000;174(7):290-319.

20. Oakes JM. The (mis) estimation of neighborhood effects: causal inference for a practicable social epidemiology. Soc Sci Med. 2004;58(10):1929-52. https://doi.org/10.1016/j.socscimed.2003.08.004. 
21. Hill CP, Bilge P, Bilge S. Intersectionality. Cambridge: Key Concepts Series; 2016.

22. Crenshaw KW. On intersectionality: Essential writings. Columbia: The New Press; 2017.

23. Shields SA. Gender: an intersectionality perspective. Sex Roles. 2008;59(5): 301-11. https://doi.org/10.1007/s11199-008-9501-8.

24. Kapilashrami A, Hill S, Meer N. What can health inequalities researchers learn from an intersectionality perspective? Understanding social dynamics with an inter-categorical approach? Soc Theory Health. 2015;13(3):288-307. https://doi.org/10.1057/sth.2015.16.

25. Mays N, Pope C. Qualitative research: rigour and qualitative research. BMJ. 1995;311(6997):109-12. https://doi.org/10.1136/bmj.311.6997.109.

26. BakamaNume BB. A contemporary geography of Uganda. Dar es salaam: African Books Collective; 2010.

27. Statistics UBO. Statistical abstract. Kampala: Uganda Bureau of Statistics; 2013.

28. Johnston LG, Sass J, Acaba J, Cheng WS, Mark Prabhu S. Ensuring inclusion of adolescent key populations at higher risk of HIV exposure: recommendations for conducting biological behavioral surveillance surveys. JMIR Public Health Surveill. 2017;3(2):e40. https://doi.org/10.2196/publichea Ith.7459.

29. Israel G. Determining sample size: University of Florida Cooperative Extension Service, Institute of Food and Agriculture Sciences, EDIS; 1992. Fact Sheet PEOD-6; 2013.

30. Kleinman A. Four social theories for global health. Lancet. 2010;375(9725): 1518-9. https://doi.org/10.1016/S0140-6736(10)60646-0.

31. Kleinman A. Patients and healers in the context of culture: An exploration of the borderland between anthropology, medicine, and psychiatry. Vol. 3. California: Univ of California Press; 1980

32. Twigg L. Geographies of space, place, and population health. The Wiley Blackwell encyclopedia of health, illness, behavior, and society; 2014. p. 726-31.

33. Dingake OBK. The state of human rights in relation to key populations, HIV and sexual and reproductive health. Reprod Health Matters. 2018;26(52):4650. https://doi.org/10.1080/09688080.2018.1543992.

34. Engel DMC, Paul M, Chalasani S, Gonsalves L, Ross DA, Chandra-Mouli V, et al. A package of sexual and reproductive health and rights interventions - what does it mean for adolescents? J Adolesc Health. 2019; 65(6):S41-50. https://doi.org/10.1016/j.jadohealth.2019.09.014.

35. Ong KKX, Ng JS, Om C, Chhoun P, Tuot S, Yi S. Perceived barriers and facilitators in using text and voice messaging for improving HIV and sexual and reproductive health of female entertainment workers in Cambodia: a qualitative study. Mhealth. 2020;6:38. https://doi.org/10.21037/mhealth.2020.04.01.

36. Senior KA, Chenhall RD. Boyfriends, babies and basketball: present lives and future aspirations of young women in a remote Australian Aboriginal community. J Youth Stud. 2012;15(3):369-88. https://doi.org/10.1080/136762 61.2012 .663890

37. Woog V, Kågesten A. The sexual and reproductive health needs of very young adolescents aged 10-14 in developing countries: what does the evidence show? 2017.

38. Kennedy EC, Bulu S, Harris J, Humphreys D, Malverus J, Gray NJ. "Be kind to young people so they feel at home": a qualitative study of adolescents' and service providers' perceptions of youth-friendly sexual and reproductive health services in Vanuatu. BMC Health Serv Res. 2013;13(1):1-12. https://doi. org/10.1186/1472-6963-13-455.

39. Kakaire O, Kaye DK, Osinde MO. Male involvement in birth preparedness and complication readiness for emergency obstetric referrals in rural Uganda. Reprod Health. 2011;8(1):1-7. https://doi.org/10.1186/1742-47558-12.

40. Kalisa R, Malande $\mathrm{OO}$. Birth preparedness, complication readiness and male partner involvement for obstetric emergencies in rural Rwanda. Pan African Med J. 2016;25:91. https://doi.org/10.11604/pamj.2016.25.91.9710.

41. Kaye DK, et al. Male involvement during pregnancy and childbirth: men's perceptions, practices and experiences during the care for women who developed childbirth complications in Mulago hospital, Uganda. BMC Pregnancy Childbirth. 2014;14(1):1-8.

42. Nkuoh GN, Meyer DJ, Tih PM, Nkfusai J. Barriers to men's participation in antenatal and prevention of mother-to-child HIV transmission care in Cameroon, Africa. J Midwifery Women's Health. 2010;55(4):363-9. https://doi. org/10.1016/j.jmwh.2010.02.009.

43. Sialubanje C, Massar K, Hamer DH, Ruiter RAC. Reasons for home delivery and use of traditional birth attendants in rural Zambia: a qualitative study.
BMC Pregnancy Childbirth. 2015;15(1):1-12. https://doi.org/10.1186/s12884015-0652-7.

44. Winchester MS, McGrath JW, Kaawa-Mafigiri D, Namutiibwa F, Ssendegye G, Nalwoga A, et al. Routines, hope, and antiretroviral treatment among men and women in Uganda. Med Anthropol Q. 2017;31(2):237-56. https://doi. org/10.1111/maq.12301.

45. Easton SD, Saltzman LY, Willis DG. "Would you tell under circumstances like that?": Barriers to disclosure of child sexual abuse for men. Psychol Men Masculinity. 2014;15(4):460.

46. Lehman P. Running scared: Masculinity and the representation of the male body. Detroit: Wayne State University Press; 2007.

47. Fleming PJ, Lee JG, Dworkin SL. "Real men Don't": constructions of masculinity and inadvertent harm in public health interventions. Am J Public Health. 2014;104(6): 1029-35. https:/doi.org/10.2105/AJPH.2013.301820.

48. Sileo KM, et al. A scoping review on the role of masculine norms in men's engagement in the HIV care continuum in sub-Saharan Africa AIDS care. 2019.

49. Eticha T, Mesfin K. Self-medication practices in Mekelle, Ethiopia. PLoS One. 2014;9(5):e97464. https://doi.org/10.1371/journal.pone.0097464.

50. Ruiz ME. Risks of self-medication practices. Curr Drug Saf. 2010;5(4):315-23. https://doi.org/10.2174/157488610792245966.

51. Wamoyi J, Fenwick A, Urassa M, Zaba B, Stones W. "Women's bodies are shops": beliefs about transactional sex and implications for understanding gender power and HIV prevention in Tanzania. Arch Sex Behav. 2011;40(1): 5-15. https://doi.org/10.1007/s10508-010-9646-8.

52. Frohlich $\mathrm{KL}$, Corin $\mathrm{E}$, Potvin $\mathrm{L}$. A theoretical proposal for the relationship between context and disease. Sociol Health illness. 2001;23(6):776-97. https://doi.org/10.1111/1467-9566.00275.

53. Pearce J, Mitchell R, Shortt N. Place, space, and health inequalities. Health inequalities: Critical perspectives; 2015. p. 192-205.

54. Levesque J-F, Harris MF, Russell G. Patient-centred access to health care: conceptualising access at the interface of health systems and populations. Int J Equity Health. 2013;12(1):1-9. https://doi.org/10.1186/1475-9276-12-18.

55. Wilunda C, et al. Availability, utilisation and quality of maternal and neonatal health care services in Karamoja region, Uganda: a health facility-based survey. Reprod Health. 2015;12(1):1-11.

56. Tumwine $\mathrm{C}$, Aggleton $\mathrm{P}$, Bell S. Accessing HIV treatment and care services in fishing communities around Lake Victoria in Uganda: mobility and transport challenges. Afr J AIDS Res. 2019;18(3):205-14. https://doi.org/10.2989/1 6085906.2019.1648306

57. McLaren ZM, Ardington C, Leibbrandt M. Distance decay and persistent health care disparities in South Africa. BMC Health Serv Res. 2014;14(1):1-9. https://doi.org/10.1186/s12913-014-0541-1.

58. Kwiringira JN, Ariho P, Zakumumpa H, Mugisha J, Rujumba J, Mugisha MM. Livelihood risk, culture, and the HIV Interface: evidence from lakeshore border communities in Buliisa District, Uganda. J Trop Med. 2019;2019:1-10. https://doi.org/10.1155/2019/6496240.

59. Asiki G, Mpendo J, Abaasa A, Agaba C, Nanvubya A, Nielsen L, et al. HIV and syphilis prevalence and associated risk factors among fishing communities of Lake Victoria, Uganda. Sex Transm Infect. 2011;87(6):511-5. https://doi. org/10.1136/sti.2010.046805.

60. Barageine JK, Tumwesigye NM, Byamugisha JK, Almroth L, Faxelid E. Risk factors for obstetric fistula in Western Uganda: a case control study. PLoS One. 2014;9(11):e112299. https://doi.org/10.1371/journal.pone.0112299.

61. Swain D, Parida SP, Jena SK, Das M, Das H. Prevalence and risk factors of obstetric fistula: implementation of a need-based preventive action plan in a south-eastern rural community of India. BMC Womens Health. 2020;20(1): 1-10. https://doi.org/10.1186/s12905-020-00906-w.

62. Tumwine C, Aggleton P, Bell S. Enhancing HIV prevention: social support, access to, and use of HIV testing, treatment, and Care Services in Fishing Communities around Lake Victoria, Uganda. AIDS Educ Prev. 2020;32(3):196211. https://doi.org/10.1521/aeap.2020.32.3.196.

63. Curtis S, Rees Jones I. Is there a place for geography in the analysis of health inequality? Sociol Health Illness. 1998;20(5):645-72. https://doi.org/1 $0.1111 / 1467-9566.00123$

64. Mullings L, Schulz AJ. Intersectionality and Health: An Introduction. 2006.

65. Hankivsky O. Women's health, men's health, and gender and health: implications of intersectionality. Soc Sci Med. 2012;74(11):1712-20. https:// doi.org/10.1016/j.socscimed.2011.11.029.

66. Kelly UA. Integrating intersectionality and biomedicine in health disparities research. Adv Nurs Sci. 2009:32(2):E42-56. https://doi.org/10.1097/ANS.0b013 e3181a3b3fc. 
67. Chan L, Hart LG, Goodman DC. Geographic access to health care for rural Medicare beneficiaries. J Rural Health. 2006;22(2):140-6. https://doi.org/1 0.1111/j.1748-0361.2006.00022.x.

68. Tumwesigye NM, Atuyambe L, Wanyenze RK, Kibira SPS, Li Q, WabwireMangen F, et al. Alcohol consumption and risky sexual behaviour in the fishing communities: evidence from two fish landing sites on Lake Victoria in Uganda. BMC Public Health. 2012;12(1):1-11. https://doi.org/10.1186/14 71-2458-12-1069.

69. Saatcioglu B, Corus C. Poverty and intersectionality: a multidimensional look into the lives of the impoverished. J Macromark. 2014;34(2):122-32. https:// doi.org/10.1177/0276146713520600.

70. Breuer C, Bloom B, Miller AP, Kigozi G, Nakyanjo N, Ddaaki W, et al. "The bottle is my wife": exploring reasons why men drink alcohol in Ugandan fishing communities. Soc Work Public Health. 2019:34(8):657-72. https://doi. org/10.1080/19371918.2019.1666072.

71. Jones K, Duncan C. Individuals and their ecologies: analysing the geography of chronic illness within a multilevel modelling framework. Health Place. 1995;1(1):27-40. https://doi.org/10.1016/1353-8292(95)00004-6.

72. Kyei NN, Campbell OM, Gabrysch S. The influence of distance and level of service provision on antenatal care use in rural Zambia. PLoS One. 2012; 7(10):e46475. https://doi.org/10.1371/journal.pone.0046475.

73. Duff P, Kipp W, Wild TC, Rubaale T, Okech-Ojony J. Barriers to accessing highly active antiretroviral therapy by HIV-positive women attending an antenatal clinic in a regional hospital in western Uganda. J Int AIDS Soc. 2010;13(1):1-9. https://doi.org/10.1186/1758-2652-13-37.

74. Tuller DM, Bangsberg DR, Senkungu J, Ware NC, Emenyonu N, Weiser SD. Transportation costs impede sustained adherence and access to HAART in a clinic population in southwestern Uganda: a qualitative study. AIDS Behav. 2010;14(4):778-84. https://doi.org/10.1007/s10461-009-9533-2.

75. Keuroghlian AS, Frankenburg FR, Zanarini MC. The relationship of chronic medical illnesses, poor health-related lifestyle choices, and health care utilization to recovery status in borderline patients over a decade of prospective follow-up. J Psychiatr Res. 2013;47(10):1499-506. https://doi. org/10.1016/j.jpsychires.2013.06.012.

76. Ellis J, Mullan J. Prescription medication borrowing and sharing: risk factors and management. Aust Fam Physician. 2009;38(10):816-9.

77. Beyene KA, Sheridan J, Aspden T. Prescription medication sharing: a systematic review of the literature. Am J Public Health. 2014;104(4):e15-26. https://doi.org/10.2105/AJPH.2013.301823.

78. Ouma J, Jeffery C, Valadez JJ, Wanyenze RK, Todd J, Levin J. Combining national survey with facility-based HIV testing data to obtain more accurate estimate of HIV prevalence in districts in Uganda. BMC Public Health. 2020; 20(1):1-14. https://doi.org/10.1186/s12889-020-8436-z.

79. Cioffi A. Public and private health services: wait times for health services and the risk of inequality from the Italian perspective. Popul Health Manage. 2021;24(3):314-5. https://doi.org/10.1089/pop.2020.0091.

80. Johar M, Soewondo P, Pujisubekti R, Satrio HK, Adji A. Inequality in access to health care, health insurance and the role of supply factors. Soc Sci Med. 2018:213:134-45. https://doi.org/10.1016/j.socscimed.2018.07.044

81. Lazar M, Davenport L. Barriers to health care access for low income families: a review of literature. J Community Health Nurs. 2018;35(1):28-37. https:// doi.org/10.1080/07370016.2018.1404832.

82. Luchenski S, Maguire N, Aldridge RW, Hayward A, Story A, Perri P, et al. What works in inclusion health: overview of effective interventions for marginalised and excluded populations. Lancet. 2018;391(10117):266-80. https://doi.org/10.1016/S0140-6736(17)31959-1.

83. Gulliford M, Figueroa-Munoz J, Morgan M, Hughes D, Gibson B, Beech R, et al. What does' access to health care'mean? J Health Serv Res Policy. 2002; 7(3):186-8. https://doi.org/10.1258/135581902760082517.

84. Adjiwanou V, LeGrand T. Gender inequality and the use of maternal healthcare services in rural sub-Saharan Africa. Health Place. 2014;29:67-78. https://doi.org/10.1016/j.healthplace.2014.06.001.

85. Wong Y-N, Hamilton O, Egleston B, Salador K, Murphy C, Meropol NJ. Understanding how out-of-pocket expenses, treatment value, and patient characteristics influence treatment choices. Oncologist. 2010;15(6):566-76. https://doi.org/10.1634/theoncologist.2009-0307.

86. Umubyeyi A, Persson M, Mogren I, Krantz G. Gender inequality prevents abused women from seeking care despite protection given in genderbased violence legislation: a qualitative study from Rwanda. PLoS One. 2016;11(5):e0154540. https://doi.org/10.1371/journal.pone.0154540.
87. Damme WV, Leemput LV, Por I, Hardeman W, Meessen B. Out-of-pocket health expenditure and debt in poor households: evidence from Cambodia. Tropical Med Int Health. 2004;9(2):273-80. https://doi.org/10.1046/j.1365-31 56.2003.01194.x

88. Dodd R, Palagyi A, Guild L, Jha V, Jan S. The impact of out-of-pocket costs on treatment commencement and adherence in chronic kidney disease: a systematic review. Health Policy Plan. 2018;33(9):1047-54. https://doi.org/1 0.1093/heapol/czy081.

89. Cummins S, Curtis S, Diez-Roux AV, Macintyre S. Understanding and representing 'place'in health research: a relational approach. Soc Sci Med. 2007:65(9):1825-38. https://doi.org/10.1016/j.socscimed.2007.05.036.

90. Kearns RA. Place and health: towards a reformed medical geography. Prof Geogr. 1993;45(2):139-47. https://doi.org/10.1111/j.0033-0124.1993.00139.x.

91. Kwiringira J, et al. Seasonal variations and shared latrine cleaning practices in the slums of Kampala city, Uganda. BMC Public Health. 2016;16(1):1-10.

92. Duncan C, Jones K, Moon G. Do places matter? A multi-level analysis of regional variations in health-related behaviour in Britain. Soc Sci Med. 1993; 37(6):725-33. https://doi.org/10.1016/0277-9536(93)90366-C.

93. Macintyre S, Ellaway A, Cummins S. Place effects on health: how can we conceptualise, operationalise and measure them? Soc Sci Med. 2002:55(1): 125-39. https://doi.org/10.1016/S0277-9536(01)00214-3.

94. Sundararajan R, Mwanga-Amumpaire J, Adrama H, Tumuhairwe J, Mbabazi S, Mworozi K, et al. Sociocultural and structural factors contributing to delays in treatment for children with severe malaria: a qualitative study in southwestern Uganda. Am J Trop Med Hyg. 2015;92(5):933-40. https://doi org/10.4269/ajtmh.14-0784.

\section{Publisher's Note}

Springer Nature remains neutral with regard to jurisdictional claims in published maps and institutional affiliations.

Ready to submit your research? Choose BMC and benefit from

- fast, convenient online submission

- thorough peer review by experienced researchers in your field

- rapid publication on acceptance

- support for research data, including large and complex data types

- gold Open Access which fosters wider collaboration and increased citations

- maximum visibility for your research: over $100 \mathrm{M}$ website views per year

At BMC, research is always in progress.

Learn more biomedcentral.com/submissions 